\section{More on the travesty of pre-authorization}

We were delighted to read Dr. Nasrallah's coruscating editorial about the deceptive, unethical, and clinically harmful practice of insurance companies requiring pre-authorization before granting coverage of psychotropic medications that are not on their short list of inexpensive alternatives ("Pre-authorization is illegal, unethical, and adversely disrupts patient care." From the Editor, Current Psychiatry. April 2020, p. 5, 10-11). Obtaining pre-authorization is time-consuming for busy doctors, often prohibitively so-and sometimes simply impossible, regardless of the time and effort invested. In this way, insurers can cleverly withhold optimal treatment while still being able to assert that they will cover all "medically necessary" treatments, as initially determined by a nonphysician reviewer working from a checklist.

Brian S. Barnett, MD Staff Psychiatrist Cleveland Clinic Lutheran Hospital Cleveland, Ohio

J. Alexander Bodkin, MD Chief

Clinical Psychopharmacology Research Program McLean Hospital Harvard Medical School Belmont, Massachusetts

Disclosures: The authors report no financial relationships with any companies whose products are mentioned in this article, or with manufacturers of competing products.

\section{Keep in touch!}

\section{letters@currentpsychiatry.com}

\section{OR}

Comments \& Controversies

CURRENT Psychiatry

7 Century Drive, Suite 302

Parsippany, NJ 07054

All letters are subject to editing.
I thank Dr. Nasrallah for bringing up the issue of pre-authorization in his editorial and could not agree with him more. As a practicing geriatric psychiatrist-for several decades-I experienced all of what he so nicely summarized, and more. The amount and degree of humiliation, frustration, and (mainly) waste of time have been painful and unacceptable. As he said: It must be stopped! The question is "How?" Hopefully this editorial triggers some activity against pre-authorization. It was time somebody addressed this problem.

\section{Istvan Boksay, MD, PhD Private psychiatric practice New York, New York}

Disclosure: The author reports no financial relationships with any companies whose products are mentioned in this article, or with manufacturers of competing products.

I thank Dr. Nasrallah for his editorial about pre-authorization, which was well organized and had a perfect headline. In succinct paragraphs, it says what we practitioners have wanted to say for years. If only the American Psychiatric Association and American Medical Association would take up the cause, perhaps some limitations might be put on this corporate intrusion into our practice. Pre-authorization may save insurance companies money, but its cost in time, frustration, and clinical outcomes adds a considerable burden to the financial problems of health care in the United States.

John Buckley, MD

Private psychiatric practice Glen Arm, Maryland

Disclosure: The author reports no financial relationships with any companies whose products are mentioned in this article, or with manufacturers of competing products.

I thank Dr. Nasrallah so much for his editorial. These types of clinically useless administrative tasks are invisible barriers to mental health care access, because the time utilized to complete

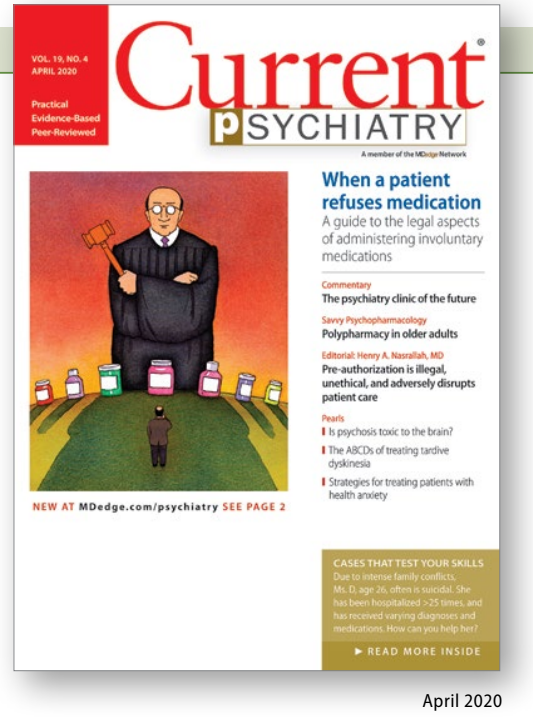

these tasks can easily be used to see one more patient who needs to be treated. However, I also wonder how we as psychiatrists can move forward so that our psychiatric organizations and legislative bodies can take further action to the real barriers to health care and effective interventions.

Ranvinder Kaur Rai, MD

Private psychiatric practice Fremont, California

Disclosure: The author reports no financial relationships with any companies whose products are mentioned in this article, or with manufacturers of competing products.

I read with interest Dr. Nasrallah's editorials "We are physicians, not providers, and we treat patients, not clients!" (From the Editor, Current Psychiatry. February 2020, p. 5,10-11) and "Pre-authorization is illegal, unethical, and adversely disrupts patient care." I can't help but link the 2 editorials together.

Dr. Nasrallah's strong advocacy against the use of the term "provider" is long overdue. I distinctly remember the insidious onset of the use of the terms provider and "consumer" during my years as a medical director of a mental health center. The inception of the provider/consumer terminology can be construed as striving for cultural correctness when psychiatry was going through its own identity crisis in response to deinstitutionalization 
and the destruction of the so-called myth of psychiatrists as paternalistic and all-powerful. Managed care as the business model of medicine further destroyed the perception of the psychiatric physician as noble and caring, and demythologized the physician-patient relationship. It is amazing how the term provider has persisted and become part of the language of medicine. During the last 20 years or so, psychiatric and medical professional organizations have done little to squash the usage of the term.
Furthermore, the concept of preauthorization is not new to medicine, but has insidiously become part of the tasks of the psychiatric physician. It has morphed into more than having to obtain approval for using a branded medication over a cheaper generic alternative to having to obtain approval for the use of any medication that does not fall under the approved tier. Even antipsychotics (generally a protected class) have not been immune.

Both the use of the term provider and the concept of pre-authorization require more than the frustration and indignation of a clinical psychiatrist. It requires the determination of professional psychiatric organizations and those with power to fight the gradual but ever-deteriorating authority of medical practice and the role of the psychiatric physician.

Elizabeth A. Varas, MD Private psychiatric practice Westwood, New Jersey

Disclosure: The author reports no financial relationships with any companies whose products are mentioned in this article, or with manufacturers of competing products. 